\title{
Trombosis venosa seguida de una hemorragia cerebral en un paciente con síndrome antifosfolipídico
}

\section{Venous thrombosis following brain hemorrhage in a patient with antifospholipid syndrome}

Correspondencia Giancarlo Francois Castillo Tarrillo giancarlocastillot@gmail.com

Recibido: $17 / 01 / 2017$ Aprobado: 01/02/2017

Citar como: Castillo-Tarrillo GF, Vetanzo-Sánchez G, SánchezHurtado L. Trombosis venosa seguida de una hemorragia cerebral en un paciente con sindrome antifosfolipídico [carta]. Acta Med Peru. 2017;34(2):159-61

\author{
Giancarlo F. Castillo-Tarrillo1,2, Georgette Vetanzo-Sánchez ${ }^{1,2}$, Luis Sánchez- \\ Hurtado ${ }^{3}$ \\ 1 Universidad Nacional Mayor de San Marcos. Lima, Perú. \\ 2 Sociedad Científica de San Fernando. Lima, Perú. \\ 3 Hospital Nacional Arzobispo Loayza. Lima, Perú. \\ a Estudiante de Medicina Humana, b Médico Internista.
}

\section{Sr. Editor:}

El síndrome antifosfolipídico (SAF) es una enfermedad multisistémica caracterizada por presentar fenómenos trombóticos vasculares y morbilidad fetal, hallazgos que sumados a la presencia de anticuerpos antifosfolípidos, inhibidores lúpicos y anticuerpos anticardiolipina en 2 o más tomas realizadas en al menos 12 semanas confirman el diagnóstico ${ }^{[1]}$. Se estima que su prevalencia es de 40 50 casos por cada 100000 personas ${ }^{[2]}$. En el 53,1\% de los casos es primario, siendo el resto asociado a otros trastornos inmunológicos como lupus eritematoso sistémico (LES), anemia hemolítica autoinmune $(\mathrm{AHA})$ y síndrome de Evans $(\mathrm{SE})^{[2,3]}$.

Se presenta el caso de un paciente varón de 26 años que acudió a emergencia por presentar cefalea holocraneana desde hace cinco días e ictericia en escleras. Un día antes del ingreso, presentó intensificación de cefalea "que no cedía a uso de analgésicos" y sensación de alza térmica. Entre los antecedentes de importancia, se registra el diagnóstico de SAF y SE hace ocho años. El paciente refirió consumir diariamente warfarina $(5 \mathrm{mg}$ ) y prednisona $(50 \mathrm{mg}$ ); sin embargo, reconocía haber ingerido irregularmente la medicación desde hace un mes. Adicionalmente, consumía $500 \mathrm{mg}$ de calcio y $1 \mathrm{mg}$ de ácido fólico al día. En los antecedentes familiares, la madre tenía los diagnósticos de hipotiroidismo y artritis reumatoide.

Al examen físico, las funciones vitales se encontraron estables. El paciente mostraba una palidez marcada e ictericia en conjuntivas. No se halló linfoadenomegalia. En el examen preferencial, se identificó un soplo sistólico II / VI multifocal, danza arterial, esplenomegalia y ligera rigidez de nuca. Con ello, los signos y síntomas identificados se agruparon en los síndromes meníngeo y anémico-ictérico, y se estableció el diagnóstico presuntivo de meningitis bacteriana.

En el hemograma, se halló trombocitopenia moderada (95000 cel/mm3), tanto la serie roja como la blanca no mostraban alteraciones. El tiempo de protrombina fue de 12,3 s, INR de 1,04, deshidrogenasa láctica en $598 \mathrm{UI} / \mathrm{L}$ y test de Coombs 4+. El valor sanguíneo de glucosa y la evaluación de la función renal y hepática fueron normales. El examen de VIH fue no reactivo, al igual que las pruebas para hepatitis B y sífilis. La tomografía cerebral no mostró anormalidades.

Al tercer día de hospitalización, el paciente desarrolló signos de aumento de la presión intracraneal; con una cefalea holocraneana que se intensificó gradualmente, asociándose el trastorno de la conciencia. Al examen físico se registró frecuencia cardiaca: 42 latidos/min, frecuencia respiratoria: 


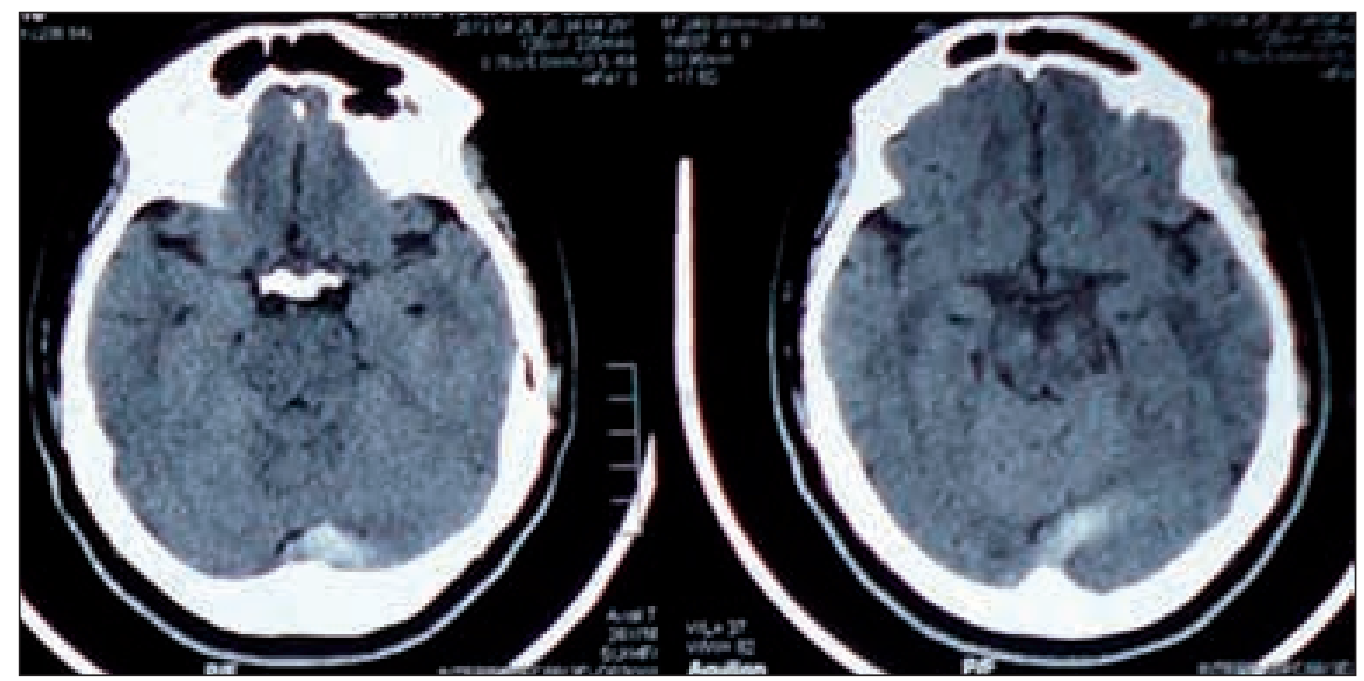

Figura 1. Tomografía axial computarizada cerebral sin contraste. Se observa una hiperdensidad en el área de la cisterna posterior.

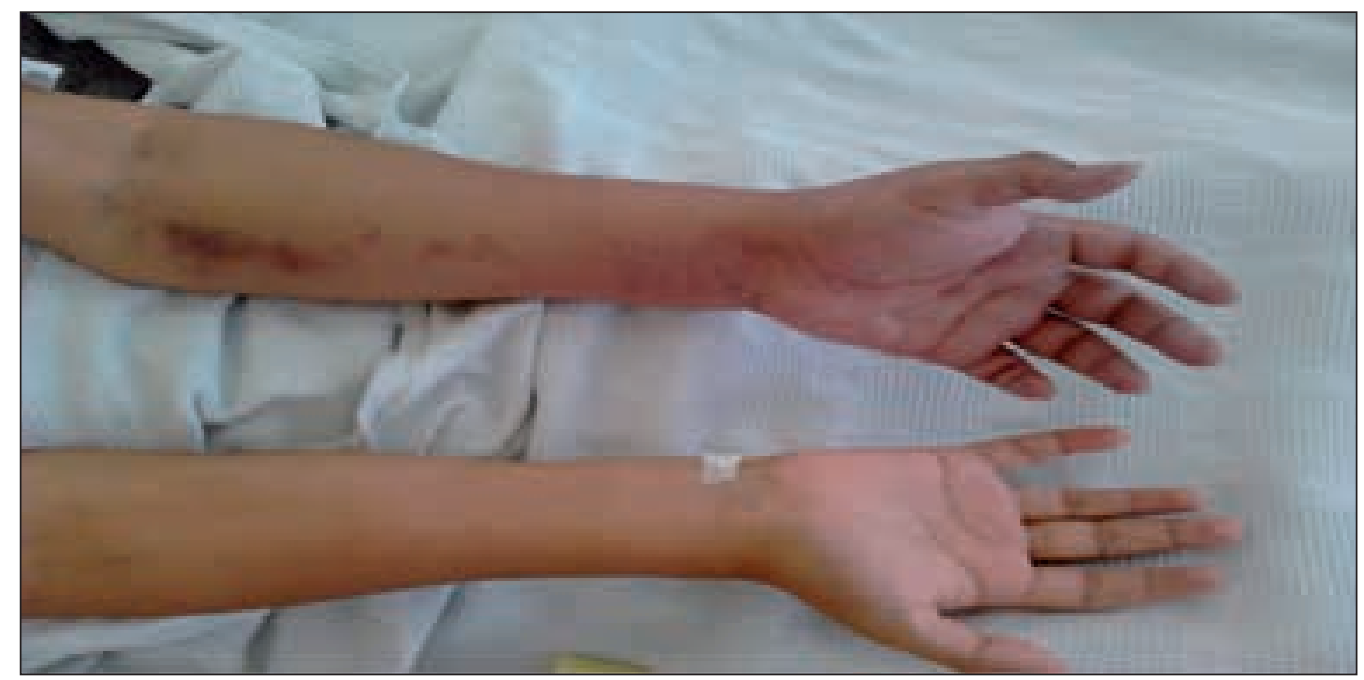

Figura 2. Edema del miembro superior izquierdo. Trombosis de la vena cefálica del brazo izquierdo.

18 respiraciones/min y presión arterial: $130 / 80 \mathrm{mmHg}$. Se dio el diagnóstico de enfermedad cerebro vascular (ECV) de tipo hemorrágico. Se solicitó tomografía cerebral (Figura 1) que mostró una zona hiperdensa en cisterna posterior. Se inició tratamiento con manitol, mejorando su estado clínico. En el hemograma se presentó una trombocitopenia severa (40 000 $\mathrm{cel} / \mathrm{mm} 3$ ) por lo que se indicó la transfusión de 4 unidades de plaquetas.

Al cuarto día de hospitalización, presentó edema del miembro superior izquierdo desde el codo a la mano izquierda; de consistencia dura y caliente sin signos de cianosis (Figura 2). Se planteó como diagnóstico una trombosis venosa profunda, que se confirmó con una ecografía doppler venosa. Finalmente, se prescribió el uso de enoxaparina seguido de anticoagulación terapéutica con warfarina, lográndose la mejora del estado general del paciente.
La ECV es una de las principales causas de muerte en pacientes con SAF, junto a las infecciones bacterianas, malignidad y el infarto agudo de miocardio ${ }^{[3]}$. El paciente presentó una ECV isquémica que luego paso a desarrollarse una hemorragia subaracnoidea produciendo un síndrome de hipertensión endocraneana. El diagnóstico de SAF se debe sospechar en pacientes con ECV menores de 50 años ${ }^{[4]}$. Esta condición tiene una prevalencia de $19,8 \%$, siendo una de las manifestaciones neurológicas más comunes junto con la migraña ${ }^{[5]}$. Si bien el SAF es más prevalente en mujeres, no existe diferencia respeto a sexo según cohortes de pacientes que presentaron ECV. El origen más frecuente es el cardioembólico; sin embargo, en la mayoría de casos no se logra identificar la causa. Por otro lado, un estudio ha sugerido una posible asociación entre la IgM anticardiolipina y la gravedad del ECV, mientras que el aumento de la IgG anti-beta-2-glicoproteina I se correlacionaría con un mal pronóstico, los que nos muestra la importancia de los anticuerpos en la fisiopatología ${ }^{[6]}$. 
Por otro lado, el estado de hipercoagulación presente en el SAF condujo a la trombosis venosa profunda del brazo izquierdo. Esta localización es infrecuente, con una prevalencia de 3,4\%, dándose generalmente en las extremidades inferiores o en el pulmón ${ }^{[5]}$, aunque la presencia del catéter venoso pudo haber aumentado el riesgo de trombosis ${ }^{[7]}$. Otros de los diagnósticos identificados fueron la AHA y la trombocitopenia, que se encuentran en el $9,7 \%$ y $29,6 \%$ de los pacientes con SAF activo, respectivamente ${ }^{[5]}$. Nuestro paciente tenía el antecedente de SE, caracterizado por la asociación de una AHA y trombocitopenia, que no era tratado de manera regular según lo manifestado por el paciente. Existen pocos reportes de la simultaneidad clínica de ambos síndromes ${ }^{[8]}$.

Dentro de los diagnósticos diferenciales, se plantearon las opciones de un brote de LES o una vasculitis debido a la asociación que existe entre enfermedades inmunológicas ${ }^{[3]}$. Sin embargo, no se realizó más pruebas por la evolución favorable. Con respecto al tratamiento, en un primer momento, la eliminación de los anticuerpos antifosfolipídico debe ser la prioridad, y puede ser conseguida con la administración de esteroides a dosis alta, inmunosupresión con ciclofosfamida o plasmaféresis para luego establecer una anticoagulación con warfarina, manteniendo el INR en valores de 2,0-3,0. La trombocitopenia se puede tratar con prednisona y de ser refractaria, rituximab ${ }^{[4]}$. Sin embargo, una terapia excesiva, un INR lábil, las interaccionas medicamentosas y enfermedades hepáticas o renales ocasionan complicaciones hemorrágicas en estos pacientes ${ }^{[9]}$. En conclusión, las complicaciones hemorrágicas y trombóticas en estos pacientes pueden llegar a ser mortales por lo que se recomienda una identificación rápida de estas condiciones para un manejo adecuado y oportuno.

\section{REFERENCIAS BIBLIOGRÁFICAS}

1. Miyakis S, Lockshin MD, Atsumi T, Branch DW, Brey RL, Cervera $R$, et al. International consensus statement on an update of the classification criteria for definite antiphospholipid syndrome (APS). J Thromb Haemost. 2006;4(2):295-306.

2. Comellas-Kirkerup L, Hernández-Molina G, Cabral AR. Antiphospholipid-associated thrombocytopenia or autoimmune hemolytic anemia in patients with or without definite primary antiphospholipid syndrome according to the Sapporo revised classification criteria: a 6-year follow-up study. Blood. 2010;116(16):3058-63.

3. Cervera R, Serrano R, Pons-Estel GJ, Ceberio-Hualde L, Shoenfeld Y, de Ramón E, et al. Morbidity and mortality in the antiphospholipid syndrome during a 10-year period: a multicentre prospective study of 1000 patients. Ann Rheum Dis. 2015;74(6):1011-8.

4. Gómez-Puerta JA, Cervera R. Diagnosis and classification of the antiphospholipid syndrome. J Autoimmun. 2014;48-49:20-5.

5. Cervera R, Piette J-C, Font J, Khamashta MA, Shoenfeld Y, Camps MT, et al. Antiphospholipid syndrome: clinical and immunologic manifestations and patterns of disease expression in a cohort of 1,000 patients. Arthritis Rheum. 2002;46(4):1019-27.

6. Rodríguez-Sanz A, Martínez-Sánchez P, Prefasi D, Fuentes B, PascualSalcedo D, Blanco-Bañares MJ, et al. Antiphospholipid antibodies correlate with stroke severity and outcome in patients with antiphospholipid syndrome. Autoimmunity. 2015;48(5):275-81.

7. Lim W. Antiphospholipid antibody syndrome. Hematol Am Soc Hematol Educ Program. 2009;233-9.

8. Khalifa M, Ghannouchi N, Kaabia N, BenJazia E, Hachfi W, Krifa A, et al. Primary antiphospholipid syndrome and Evan's syndrome: 2 case reports. Acta Clin Belg. 2009;64(1):65-7.

9. Pazzola G, Zuily S, Erkan D. The challenge of bleeding in antiphospholipid antibody-positive patients. Curr Rheumatol Rep. 2015;17(2):7.

\title{
Las ediciones anteriores de Acta Médica Peruana están disponibles en:
}

\author{
www.redalyc.org
}

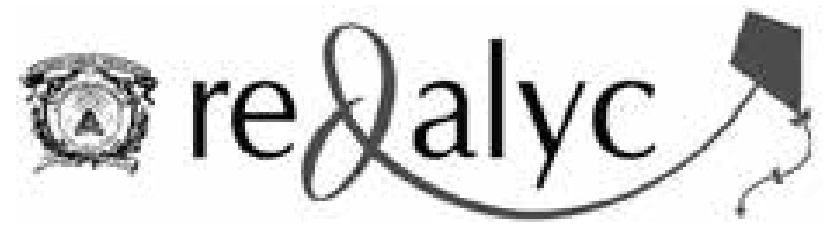

